\title{
TCOM \\ Creating opportunities to discuss the nature of Japanese science communication
}

\section{Reviewed Conference}

Reviewed by

Abstract

Keywords

DOI

Overview

\author{
BUILD SCICOMM, \\ UNIVERSITY of TSUKUBA, TSUKUBA, IBARAKI, JAPAN, November 2019
}

\section{Mitsuru Kudo and Matthew Wood}

Build SciComm, an international symposium on strategies for fostering science communication in Japan held at the University of Tsukuba in November 2019, brought together academics and practitioners to discuss issues faced by the field in Japan and vision for future direction. Informally, the symposium was well received and generally considered to be a useful and stimulating event. We discuss issues to be considered for future incarnations and explain why this symposium provides an important forum for inclusive discussions on fundamental questions about the nature of science communication in Japan.

Professionalism, professional development and training in science communication; Public engagement with science and technology

https://doi.org/10.22323/2.19010602

Submitted: 25th December 2019

Accepted: 13th January 2020

Published: 29th January 2020

In this paper we reflect on the outcomes of an international symposium on science communication titled Build SciComm, hosted by the University of Tsukuba, Japan, in November 2019. ${ }^{1}$ Seven domestic speakers (i.e. those based at and working for universities in Japan) and three non-Japan-based speakers comprised the panels in four sessions. One of the authors (Wood) was the primary coordinator of the event, and the other author (Kudo) was involved in planning, design and organisation, and participated in the symposium as a speaker.

Subtitled "An international symposium on strategies for fostering science communication in Japan", one of the primary motivations behind the symposium was our concern that science communication - as a field for both research and practice for building more open, inclusive and participatory relationships between

\footnotetext{
${ }^{1}$ https:/ / buildscicomm.eventcreate.com.
} 
publics and sciences - has begun to languish in recent years in Japan. Since the launch of a series of science communicator training programmes at university level in 2005, there have been a wide range of activities in training, education, and practice under the banner of science communication. Science communication has been used as a label to signpost platforms where people from differing practical and scholarly backgrounds gather together and openly discuss how to collaborate and promote communication with the public about science and technology. Yet, there appears to be some concern amongst many of those who are involved with science communication in Japan that the field has begun to lose momentum. Discussions with colleagues often reveal a general sense that government and institutional enthusiasm for science communication has waned and that funding for new projects and educational programs has become more difficult to secure. Therefore, the aim of the symposium was to explore pathways and strategic approaches for us to guard against a loss of momentum and to ensure a vibrant future for Japanese science communication.

In preparation for the symposium, four key themes were identified as important for a discussion on the future direction for the field. These themes were as follows: 1) The nature of science communication in Japan, and the qualities necessary for it to fit comfortably within the Japanese cultural framework and to address this country's specific social needs; 2) Opportunities stemming from international collaboration on science communication projects, both to the benefit of Japan and Japanese science communication, as well as for contribution to the international science communication movement; 3) Approaches to science communication training and education which are appropriate for the needs of the country; and 4) Strategies (including social, political, academic, or other) for fostering an environment in which science communication is recognised and valued, and in which the field can thrive. These themes were addressed in separate sessions which took the form of short talks followed by a panel discussion and Q\&A. In this way input was drawn not only from speakers, but also from attendees.

Over 70 participants (speakers and attendees) took part in the event including academics, researchers, educators, public information officers, writers, museum curators, science centre interpreters, and students. Speakers shared their opinions and experience related to the four themes, and attendees contributed actively to the mediated discussions which followed. The result was a broad and candid exploration of issues faced by science communication in Japan, and future vision for the field. Some notable examples were a comparison between Japan and other countries revealing similarities in a developmental arc from science propaganda to public engagement - although different countries are at different points on that arc - as well as similarities in influences of major societal events such as natural disasters. The discussion also revealed differences in how cultural and social values shape the real world implementation of science communication. Indigenous influence on policy has been notable in New Zealand, and experiences of the Science Media Centre of Japan, especially during the period immediately following the Great East Japan Earthquake and the subsequent radioactive contaminations caused by the nuclear power plant accidents in Fukushima in 2011, highlighted differences in media-expert relationships between countries. There was also broad agreement that clear goals for the field, both at the level of individual activities and government and institutional frameworks are critical for the development of the field, and that these goals should be justifiable, not only from an idealistic 
standpoint of what science communication 'should' be, but also in terms of policy priorities and other constraints on practical implementation.

\section{A forum for inclusive discussions}

Overall, the symposium was a productive and useful forum - a view that was echoed informally by many in attendance - and we are now considering organising a second gathering to continue the discussion and promote more collaborative initiatives. In preparation for this, we have considered some constructive criticism that emerged. Although issues pertaining to practice were also discussed, the symposium largely focussed on a discussion of basic questions about science communication such as what it is/should be and what its role is/should be in society - questions which have been given increasing attention in academic discussion on science communication for some time now - and did not arrive at guidelines for specific actions or policy recommendations. While acknowledging that these points may be cause for concern in some contexts, in what follows we will discuss the importance of creating opportunities for interested and concerned academics and practitioners to gather and discuss the fundamental and yet unanswered questions regarding the raison d'être of science communication.

As a field in which practical discussion is central to its interest and concern in many ways, questions about "how" (e.g. how should it be conducted?) have always been vitally important in science communication. These questions have guided the last several decades of development of science communication in its fields of practice such as science education, science journalism, public relations of scientific research institutes, citizen science, and public participation in scientific decision-making. However, in recent studies about science communication, while many continue working on this practice-driven exploration into better design and execution of science communication, growing attention is being paid to asking "why" of science communication [e.g. Stilgoe, Lock and Wilsdon, 2014]. For science communication to progress, we are required to "mak[e] different value orientations within the science communication community much more explicit and visible, using a framework to identify, uncover, and map out unspoken, hidden or unconscious values" [Ogawa, 2013, p. 7]. Pursuit of "best practice" in any given area of science communication will probably remain important, but it should be accompanied by critical self-reflection [Chilvers, 2012]. This also includes consideration of the role of science communication as a cultural activity, making meaning within a society [Davies et al., 2019].

Discussion of fundamental questions about the values underpinning the promotion of science communication as a field in Japan requires input from both academia and practice, yet a forum or opportunity for such a discussion has not been sufficiently realised. For example, although we have an open access science communication journal, which plays a key role in developing scholarly informed discussion on the topic, the strict academic framework may act as a barrier to more fluid and inclusive conversations. In such a situation, it is of significant value to create opportunities like Build SciComm for both practitioners and thinkers of science communication to gather together and discuss "why" questions about science communication in an open, frank and mutually-respecting manner. 
The appeal of such an opportunity for collective self-reflection was evidenced by the diversity of attendees, and a desire for even more inclusivity was indicated through the constructive feedback we received. As mentioned earlier, although there were a broad range of academics and professionals in attendance, the speakers were limited to university academics, and there were no professional or practitioner speakers who could offer perspectives from outside a university context. Future incarnations of Build SciComm should further foster the merit of the event through broader representation among speakers, topics which span theory, research, and practice, and explicit declarations of the role of the symposium as a forum for the convergence of conceptual views and pragmatic realities.

\section{Concluding thoughts}

Acknowledgments

We are sincerely grateful to the following speakers and contributors to the symposium content: Tatsuro Ayatsuka, Brendan Barrett, Kohei Ishigami, Kei Kano, Shishin Kawamoto, Sara Kobayashi, Rod Lamberts, Nancy Longnecker, Jenny Martin, Linda Sellou, Mikihito Tanaka, Masataka Watanabe, and Hiromi Yokoyama. We are also equally grateful to all the symposium attendees for their active participation in discussions. Thank you to BB, KK, SK, NL, LS, and HY for their review of the manuscript and constructive comments. The event was funded by the Education Strategy Promotion Project Support Program of the University of Tsukuba.

\section{References}

Discussion at Build SciComm did not feed directly into policy, nor did it share practical tips. Instead of this, and exactly because of such situational conditions, the participants could take a moment to reflect on "why science communication?" together, without seeking immediate solutions to issues they had in their practical contexts. The key here is to promote such reflection as a collaborative, co-productive action, rather than delegate it to individuals to ponder in isolation. By offering a forum for such discussion, Build SciComm filled an important niche in the landscape of Japanese science communication networks, conferences, and communication channels, and succeeded in its goal of providing a space to enunciate the challenges facing science communication in Japan and in clearly outlining the inflection point that science communicators have reached. It has laid the groundwork for further discussions that can address strategic directions and policy as well as provide a forum for inclusive conversations about science communication practice. 
Ogawa, M. (2013). 'Towards a “design approach" to science communication'. In: Communication and engagement with science and technology: issues and dilemmas. Ed. by J. K. Gilbert and S. M. Stocklmayer. New York, U.S.A. and London, U.K.: Routledge, pp. 3-18.

Stilgoe, J., Lock, S. J. and Wilsdon, J. (2014). 'Why should we promote public engagement with science?' Public Understanding of Science 23 (1), pp. 4-15. https://doi.org/10.1177/0963662513518154.

Authors

Mitsuru Kudo, $\mathrm{PhD}$, is an associate professor at the Center for the Study of $\mathrm{Co}^{*}$ Design, Osaka University. Over the last ten years he has been working on several research projects on various topics in and around science communication, including science literacy, public participation, community engagement and science communication policy. He also teaches a range of science communication courses at the Osaka University. E-mail: mkudo@cscd.osaka-u.ac.jp.

Matthew Wood is an assistant professor at the University of Tsukuba, Japan, where he has lectured on science communication since 2009. Originally from a marine biology background (James Cook University, Australia) before earning a $\mathrm{PhD}$ in science communication from the National Centre for the Public Awareness of Science at the Australian National University, his current research interests include visual modes of communicating science and the role of affect in science communication. E-mail: mattwood@biol.tsukuba.ac.jp.

\section{How to cite}

Kudo, M. and Wood, M. (2020). 'Creating opportunities to discuss the nature of Japanese science communication'. JCOM 19 (01), R02. https://doi.org/10.22323/2.19010602. 